\title{
FEASIBILTY ANALYSIS OF FLANGED HOLES WITH SUPPORT OF NUMERICAL SIMULATION
}

\author{
DRĂGHICI CONSTANTIN, MIHĂILĂ FLORENTIN
}

\begin{abstract}
Material thinning is very important in the production of quality stamped products. Also, the material's Forming Limit Curve (FLC) offers important information about the material's formability. This paper presents a numerical tool and obtained results about the influence of geometrical characteristics of the flanged holes regarding feasibility prediction in sheet material forming. Finite element method is used in order to perform this numerical tool and results obtained are presented and discussed. There are also presented some observations and conclusions regarding the obtained results.
\end{abstract}

Keywords - Finite element method,Feasibility prediction, flanging holes, forming limit diagram

\section{Introduction}

In the automotive industry, most companies use numerical simulation software for simulation of the cold plastic deformation processes of the parts obtained from sheet metal and for analysis of their feasibility. This programs are based on practical experience, industrial knowledge and expertise in sheet metal forming. With its support, is possible to find different solution for every situation and also to analyse and optimize the cold plastic deformation processes [1]. Some of the factors that influence the feasibility of the parts are geometrical characteristics of their, mechanical properties of sheet material used to manufacture these parts, geometry of forming punch, relative hole diameter, the surface quality of the initial hole edge and respective friction conditions.

Using these software have resulted in major cuts of costs for the design dies, the possibility to test various technical solutions or test new innovative solutions, respectively, predict accurately the risk of defects in parts during forming processes and completely eliminating of tests laboratory.

Flanged holes (Figure 1) are used to ensure a correct position of the pieces from thin sheet obtained by cold plastic deformation in order to assemble them. Orientation and positioning of the parts are made with the help of guiding elements, called pilots.

Lecturer Eng. PhD-student DRĂGHICI CONSTANTIN / University Politehnica of Bucharest, Romania

Department of Theory of mechanisms and a robot

Feasibility Stamping Analysis Engineer, ASSYSTEM ROMANIA

Country: ROMANIA

Eng. PhD-student MIHĂILĂ FLORENTIN / RENAULT TEHNOLOGIE ROUMANIE

Feasibility Stamping Engineer, RENAULT TEHNOLOGIE ROUMANIE

Country: ROMANIA

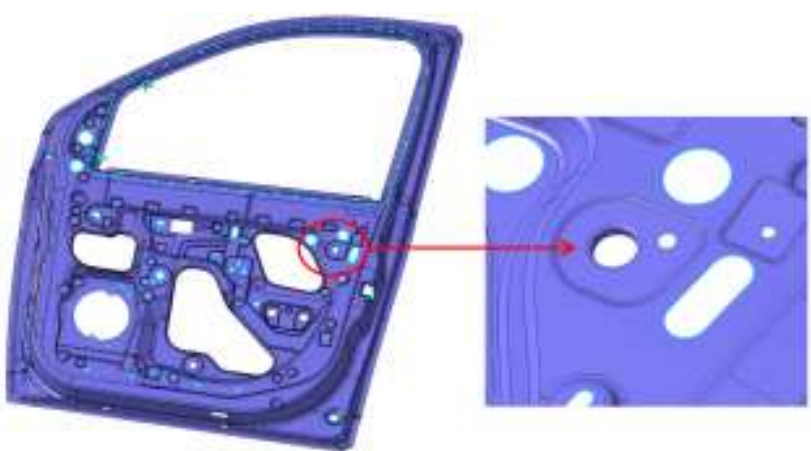

Figure 1. Flanged holes of an inner door

For the flanged holes to fulfill its functional role, they must accomplish the following conditions:

- the resulting wall height must be as high as possible

- the thinning of the wall thickness must be as small as possible

- the edges of the flanged hole must be smooth and free of cracks.

Getting them consists in forming a flange around the hole and is made in dies in two successive operations. Flanging of holes in two operations consists in an initial piercing of the blank followed by flanging, Figure 2 (a) and Figure 2 (b).

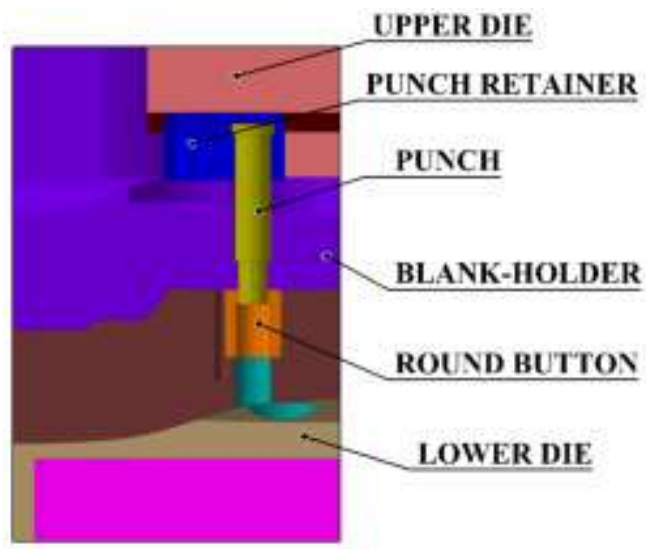

Figure 2- (a) Operation 10 - Punching 
Proc. of the Third Intl. Conf. on Advances in Mechanical and Automation Engineering - MAE 2015.

Copyright $(\odot$ Institute of Research Engineers and Doctors, USA .All rights reserved.

ISBN: 978-1-63248-080-4 doi: 10.15224/ 978-1-63248-080-4-116

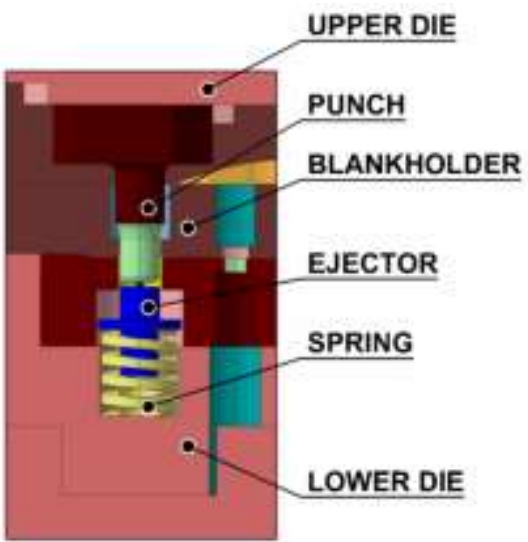

Figura 2 - (b). Operation 20 - Flanging

In [2] is presented an experimental method for determination of the limit flanging coefficient (1) using the method with two operations for obtaining flanged holes.

The limit flanging coefficient allows evaluation of feasibility under certain conditions.

$$
\mathrm{m}=\mathrm{d}_{0} / \mathrm{d}
$$

where:

$\mathrm{d}_{0}(\mathrm{~mm})$ - blank hole diameter

$\mathrm{d}(\mathrm{mm})$ - flanged hole diameter,

Values of the limit flanging coefficient cannot be very large, tables with allowable values are found in the literature given by [3] and [4].

A disadvantage of the equation (1) is that the influence of geometrical characteristics of the flanged holes regarding feasibility aren't take into account.

A modern method to quickly and accurately assess the feasibility of the flanged holes consists in simulation of the cold plastic deformation process using finite element method. Precision of results obtained using these software is so great that all major automobile manufacturers usually uses this software to analyses the feasibility of the parts from thin sheet completely eliminating of the prototyping dies. With the help of these simulations of the cold plastic deformation process, designers can modify and define parts with complex forms, feasible, that will be the basis of the future design of dies.

In this paper work a commercially - available DC04 sheet metal was used for experiments.

The main mechanical characteristics of this sheet metal are presented in table 1 .

Table 1. Mechanical characteristics of DC04 Am sheet metal

\begin{tabular}{|c|c|c|c|c|c|}
\hline Specification & $\begin{array}{c}\mathbf{0 , 2 \%} \\
\text { Yield } \\
\text { Point } \\
\mathbf{R}_{\mathbf{p} 0,2} \\
{[\mathbf{M P a}]}\end{array}$ & $\begin{array}{c}\text { Tensile } \\
\text { strength } \\
\mathbf{R}_{\mathbf{m}} \\
{[\mathbf{M P a}]}\end{array}$ & $\begin{array}{c}\text { Fracture } \\
\text { elongation } \\
\mathbf{A}_{\mathbf{8 0}} \\
{[\%]}\end{array}$ & $\begin{array}{c}\text { Vertical } \\
\text { anisotropy } \\
\mathbf{r}_{\text {min }}\end{array}$ & $\begin{array}{c}\text { Work } \\
\text { hardening } \\
\text { exponent } \\
\mathbf{n}_{\text {min }}\end{array}$ \\
\hline DC04 & 210 & $270-350$ & 38 & 1.6 & 0.18 \\
\hline
\end{tabular}

\section{Procedure in experiments}

For flanging simulation, the following actions are made:

1. Punched a rounded hole in blank

2. Blank restraining with the blank holder element, to keep the sheet samples to remain fixed between die and blank-holder

3. Punch move down to make flanged hole

4. Punch and blank holder move up

5. The feasibility of the part is evaluate with the help of Forming Limit Diagram and the resulted thinning is measured

6. The geometry is replaced with a new one and the steps from 1 to 5 are repeated

Numerical simulation of the flanging of the rounded holes was made taking in account the following three geometrical parameters, respectively, the limit flanging coefficient, $\mathrm{m}$, the blank thickness, $\mathrm{t}$, and the radius of flanged hole, $\mathrm{r}_{\mathrm{fh}}$, (Figure 3 ).

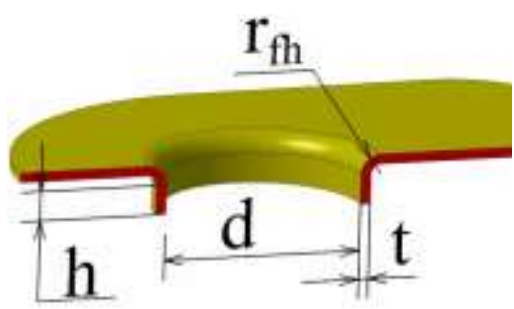

Figure 3. Geometrical characteristics of the flanging hole. where:

$\mathrm{d}(\mathrm{mm})$ - flanged hole diameter,

$\mathrm{h}(\mathrm{mm})$ - high of the wall of the flanged hole

The variation levels of the experimental data for assessing the feasibility of the flanged holes are presented in table 2 .

Table 2. The variation level of the experimental data used

\begin{tabular}{|l|c|c|c|}
\hline \multicolumn{1}{|c|}{ Independent Variables } & \multicolumn{3}{c|}{ Variation levels, in natural units } \\
\hline $\mathrm{d}_{0}$, blank hole diameter, $(\mathrm{mm})$ & 13.2 & 13.2 & 13.2 \\
\hline $\mathrm{d}$, flanged hole diameter, $(\mathrm{mm})$ & 20 & 22 & 24 \\
\hline $\mathrm{m}$, limit flanging coefficient $(\%)$ & 0,66 & 0,60 & 0,55 \\
\hline $\mathrm{t}$, thickness, $(\mathrm{mm})$ & 0,55 & 0,60 & 0,65 \\
\hline $\mathrm{r}_{\mathrm{fh}}$, radius of flanged hole $(\mathrm{mm})$ & 1 & 1.5 & 2 \\
\hline
\end{tabular}

As dependent variables it was considered the admissible thinning and feasibility. Also, for checking feasibility it was used Forming Limit Diagram (FLD).

In order to have a good precision of the results, three elements in the specimen thickness are considered, according to Table 2 . Using this solution, the thinning and feasibility can be studied.

\section{FEM simulation setup}

In this study, a commercial software was used as the FEM simulation tool, respectively, AutoForm, which is one of the best and most widely used solution in the world for analysis of parts feasibility. 
Proc. of the Third Intl. Conf. on Advances in Mechanical and Automation Engineering - MAE 2015.

Copyright (C) Institute of Research Engineers and Doctors, USA .All rights reserved.

ISBN: 978-1-63248-080-4 doi: 10.15224/ 978-1-63248-080-4-116

The numerical model presented in Fig. 4 consists in 3 rigid (punch, die and blank holder) and one deformable (specimen) bodies.

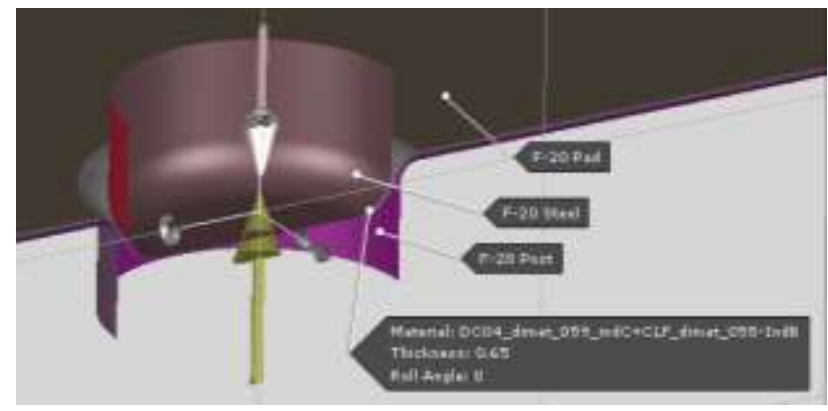

Figure 4. Numerical model

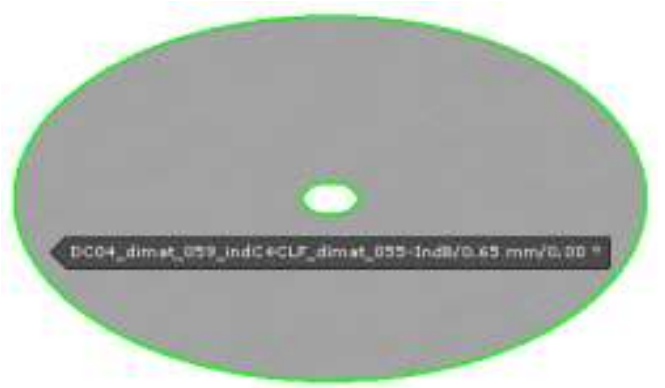

Figure 5. Schematic of the sample.

The value used for the exterior diameter, $\mathrm{D}$, was 150 $\mathrm{mm}$, and the blank hole diameter, $\mathrm{d}_{0}$, was $13.2 \mathrm{~mm}$.

The sketch of the sample used in the test is shown in Fig.5.

\section{Iv. Analysis of the obtained}

\section{results}

Obtained results from the simulation are presented in Table 3.

Table 3. Obtained results

\begin{tabular}{|c|c|c|c|c|c|c|c|c|c|}
\hline \multirow{2}{*}{$\begin{array}{c}\text { Exp. } \\
\text { nr. }\end{array}$} & \multicolumn{3}{|c|}{ Geometrical characteristics } & \multicolumn{3}{|c|}{ Independent variable } & \multirow{2}{*}{$\begin{array}{l}\text { Acceptable } \\
\text { thinning, } \varepsilon_{\mathrm{a}}, \\
\qquad(\%)\end{array}$} & \multicolumn{2}{|c|}{ Dependent variable } \\
\hline & $\begin{array}{c}\mathbf{r}_{\mathbf{p}} \\
(\mathbf{m m})\end{array}$ & $\begin{array}{c}\mathbf{d}_{\mathbf{0}} \\
(\mathbf{m m})\end{array}$ & $\begin{array}{c}\mathbf{d}, \\
(\mathbf{m m})\end{array}$ & $\begin{array}{c}\mathbf{m}, \\
(\%)\end{array}$ & $\begin{array}{c}\mathbf{r}_{\mathrm{fh}}, \\
(\mathbf{m m})\end{array}$ & $\begin{array}{c}\mathbf{t}, \\
(\mathbf{m m})\end{array}$ & & $\begin{array}{c}\text { Thinning, } \varepsilon, \\
(\%)\end{array}$ & Feasibility \\
\hline 1 & 3 & 13.2 & 20 & 0.66 & 1.0 & 0.55 & 21.5 & 20 & ok \\
\hline 2 & 3 & 13.2 & 20 & 0.66 & 1.5 & 0.55 & 21.5 & 20.3 & ok \\
\hline 3 & 3 & 13.2 & 20 & 0.66 & 2.0 & 0.55 & 21.5 & 21.2 & ok \\
\hline 4 & 3 & 13.2 & 20 & 0.66 & 1.0 & 0.60 & 21.5 & 20.3 & ok \\
\hline 5 & 3 & 13.2 & 20 & 0.66 & 1.5 & 0.60 & 21.5 & 21.1 & ok \\
\hline 6 & 3 & 13.2 & 20 & 0.66 & 2.0 & 0.60 & 21.5 & 21.6 & nok \\
\hline 7 & 3 & 13.2 & 20 & 0.66 & 1.0 & 0.65 & 22 & 26.4 & ok \\
\hline 8 & 3 & 13.2 & 20 & 0.66 & 1.5 & 0.65 & 22 & 20.4 & ok \\
\hline 9 & 3 & 13.2 & 20 & 0.66 & 2.0 & 0.65 & 22 & 21.6 & ok \\
\hline 10 & 3 & 13.2 & 22 & 0.60 & 1.0 & 0.55 & 21.5 & 23.3 & nok \\
\hline 11 & 3 & 13.2 & 22 & 0.60 & 1.5 & 0.55 & 21.5 & 25.1 & nok \\
\hline 12 & 3 & 13.2 & 22 & 0.60 & 2.0 & 0.55 & 21.5 & 25.3 & nok \\
\hline 13 & 3 & 13.2 & 22 & 0.60 & 1.0 & 0.60 & 21.5 & 24.9 & nok \\
\hline 14 & 3 & 13.2 & 22 & 0.60 & 1.5 & 0.60 & 21.5 & 25 & nok \\
\hline 15 & 3 & 13.2 & 22 & 0.60 & 2.0 & 0.60 & 21.5 & 27.4 & nok \\
\hline 16 & 3 & 13.2 & 22 & 0.60 & 1.0 & 0.65 & 22 & 25.4 & nok \\
\hline 17 & 3 & 13.2 & 22 & 0.60 & 1.5 & 0.65 & 22 & 32.2 & nok \\
\hline 18 & 3 & 13.2 & 22 & 0.60 & 2.0 & 0.65 & 22 & 24.9 & nok \\
\hline 19 & 3 & 13.2 & 24 & 0.55 & 1.0 & 0.55 & 21.5 & 29.3 & nok \\
\hline 20 & 3 & 13.2 & 24 & 0.55 & 1.5 & 0.55 & 21.5 & 29.3 & nok \\
\hline 21 & 3 & 13.2 & 24 & 0.55 & 2.0 & 0.55 & 21.5 & 29.6 & nok \\
\hline 22 & 3 & 13.2 & 24 & 0.55 & 1.0 & 0.60 & 21.5 & 29.3 & nok \\
\hline 23 & 3 & 13.2 & 24 & 0.55 & 1.5 & 0.60 & 21.5 & 29.1 & nok \\
\hline 24 & 3 & 13.2 & 24 & 0.55 & 2.0 & 0.60 & 21.5 & 30 & nok \\
\hline 25 & 3 & 13.2 & 24 & 0.55 & 1.0 & 0.65 & 22 & 29.1 & nok \\
\hline 26 & 3 & 13.2 & 24 & 0.55 & 1.5 & 0.65 & 22 & 28.9 & nok \\
\hline 27 & 3 & 13.2 & 24 & 0.55 & 2.0 & 0.65 & 22 & 29.2 & nok \\
\hline
\end{tabular}

The Forming Limit Diagram (FLD), Figure 6 (a), is a very common tool used as a failure criterion in sheet metal forming.
FLDs are used as an indication of the feasibility of a certain material, Figure 6 (b). The knowledge of the FLD is essential in order to ensure the quality of the final product by avoiding that the true strain exceeds the safe strain during the forming process. 
Proc. of the Third Intl. Conf. on Advances in Mechanical and Automation Engineering - MAE 2015.

Copyright $\odot$ Institute of Research Engineers and Doctors, USA .All rights reserved.

ISBN: 978-1-63248-080-4 doi: 10.15224/ 978-1-63248-080-4-116

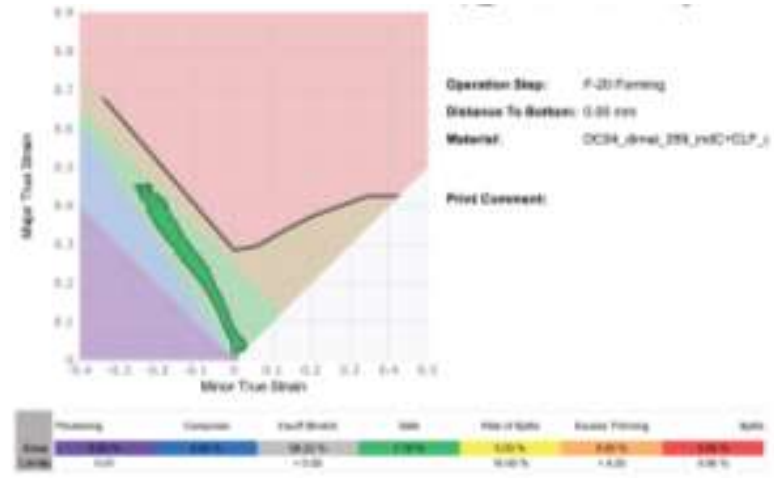

Figure 6. (a) Forming Limit Diagram
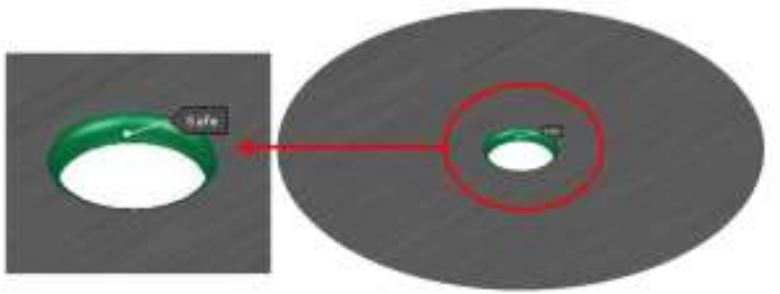

Figure 6. (b) Part feasibility representation

As can be seen, the feasibility is directly influenced by admissible thinning and vice versa. Consequently, feasible part has a maximum value of thinning in the acceptable range as shown in Figure 7 (a) and (b).

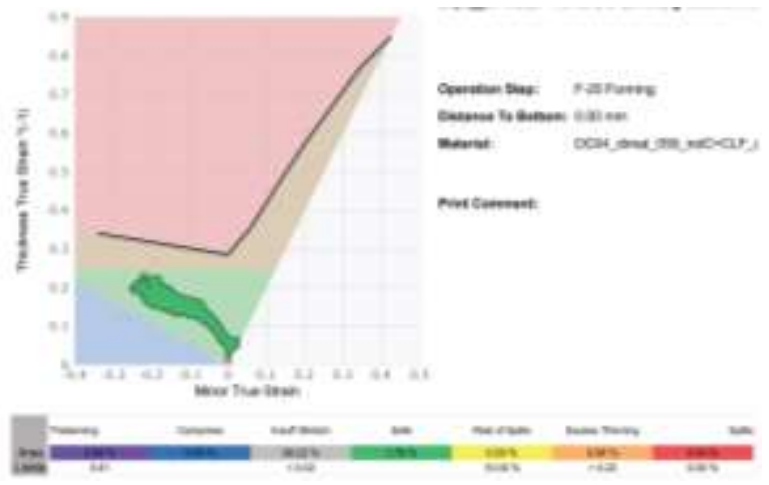

Figure 7. (a) Thinning Diagram

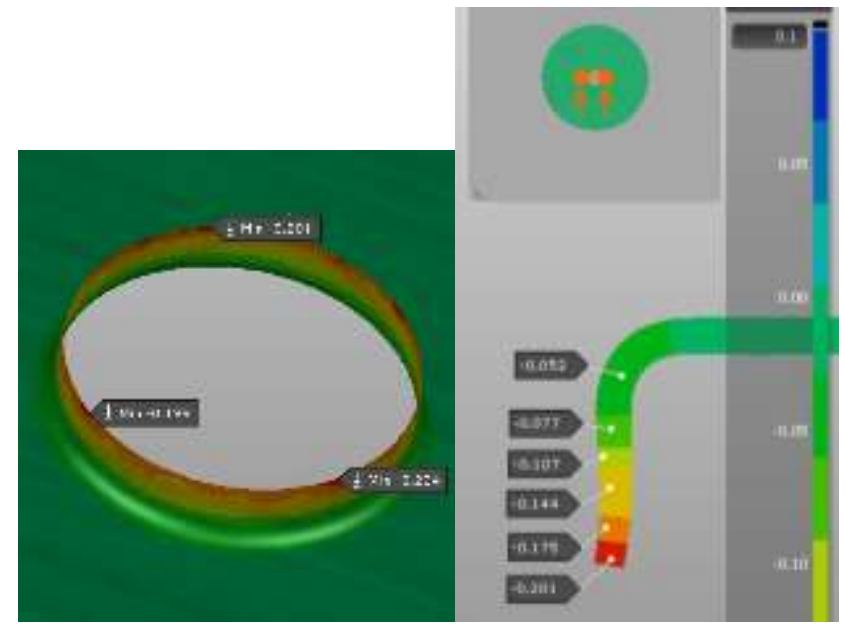

Figure 7. (b) Value of the maximum thinning
From Fig. 8, is observed that an unfeasible piece has a value of the maximum allowable thinning that exceeds accepted value.

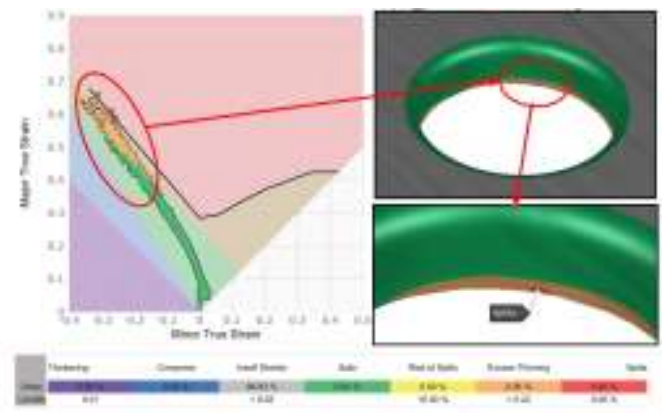

Figure 8. The relationship between feasibility and admissible thinning.

During the hole flanging process, when the punch is move down to make flanged hole and sheet is bend, the material is deformed and is expanding because of the circumferential stresses. The graph below, Figure 9, shows the relationships between the variation of thinning and limit flanging coefficient.

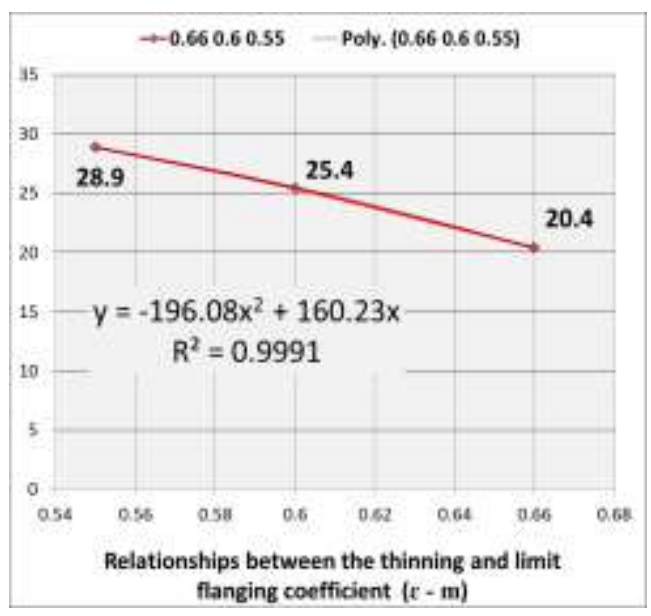

Figure 9. Relationships between the variation of thinning and limit flanging coefficient

\section{v. Observations and conclusions}

Numerical simulation allows eliminating the dies used for tests to determine the feasibility of complex parts obtained by cold plastic deformation, which is accepted and implemented by all major car manufacturers.

Numerical simulation reduces time consuming and costs; results

Numerical simulation assure good precision of the

Using numerical models can acquire data that can be the basis for optimization of the constructive characteristics of parts obtained by cold plastic deformation. 
Proc. of the Third Intl. Conf. on Advances in Mechanical and Automation Engineering - MAE 2015.

Copyright (C) Institute of Research Engineers and Doctors, USA .All rights reserved.

ISBN: 978-1-63248-080-4 doi: 10.15224/ 978-1-63248-080-4-116

The results obtained by numerical simulation, Table 3, are confirmed by their use in the manufacture of parts, as example inner doors, according to Figure 9 (a), (b) and (c) by DACIA plant.

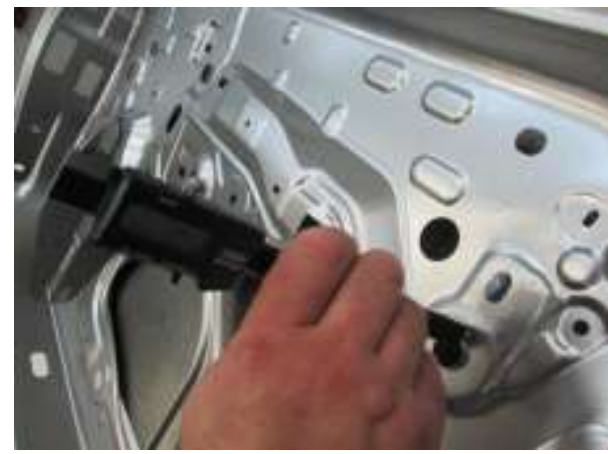

Figure 9. (a) Flanged hole validated using numerical simulation with the support of AutoFORM software Experience number 8 .

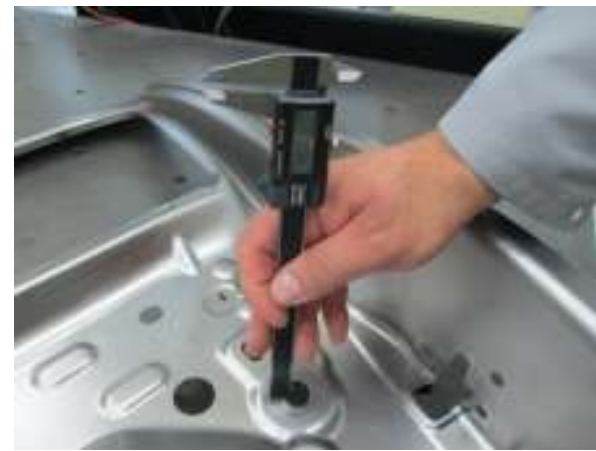

Figure 9. (b) Flanged hole validated using numerical simulation with the support of AutoFORM softwareExperience number 8 .

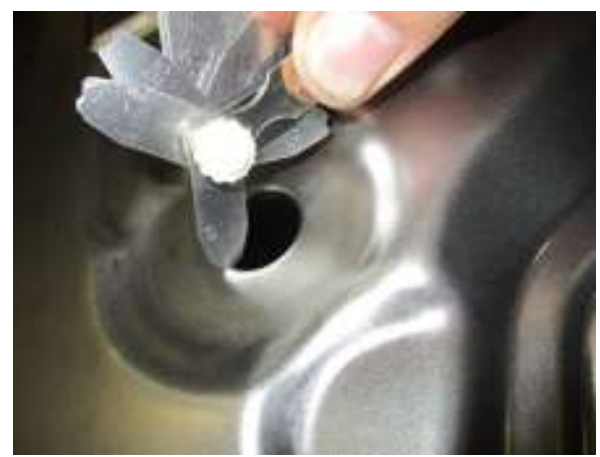

Figure 9. (c) Flanged hole validated using numerical simulation with the support of AutoFORM softwareExperience number 8 .

The numerical model used has a good flexibility based on the possibility to easy change geometrical and material parameters of the specimen and on her construction - rigid bodies group, on a side, and deformable material, to another side.

Hence, finite element method is a very important, accurate and vital tool for better and efficient design of flanged holes process.

\section{ACKNOWLEDGMENT}

The work has been funded by the Sectorial Operational Programme Human Resources Development 2007-2013 of the Ministry of European Funds through the Financial Agreement POSDRU/187/1.5/S/155536.

\section{References}

[1] Tahir Altinbalik, Aysun Tonka, NUMERICAL AND EXPERIMENTAL STUDY OF SHEET THICKNESS, VARIATION IN DEEP DRAWING PROCESSES International Journal of Modern Manufacturing Technologies, ISSN 2067-3604, Vol. IV, No. 2 / 2012, pp. 9 $-16$

[2] Gh SINDILA \& CO, TEHNOLOGII DE FABRICARE PRIN DEFORMARE PLASTICA LA RECE, EDITURA BREN, Bucuresti 2009, ISBN 978-973-648-8719, LUCRAREA NR.14 - DETERMINAREA COEFICIENTULUI LIMITA DE RASFRANGERE A MARGINILOR ORIFICIILOR CIRCULARE, pp. 115 121

[3] C. CIOCARDIA, FL. DRAGANESCU, GH. SINDILA, CRAITA CARP-CIOCARDIA SI C. PARVU, TEHNOLOGIA PRESARII LA RECE, EDITURA DIDACTICA SI PEDAGOGICA, R.A., BUCURESTI 1991, ISBN 973-30-2314-0, pp. 238 - 240

[4] STANTAREA SI MATRITAREA LA RECE, V. P. ROMANOVSKI, EDITURA TEHNICA BUCURESTI 1970, pp. 334

About Author (s):

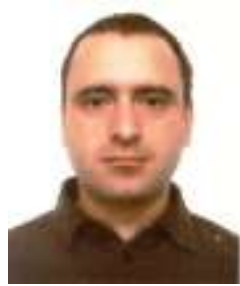

DRAGHICI CONSTANTIN is a

Lecturer and PhD-student at University Politehnica of Bucharest. He also works as Stamping Feasibility Analyst Engineer at ASSYSTEM ROMANIA for 5 years.

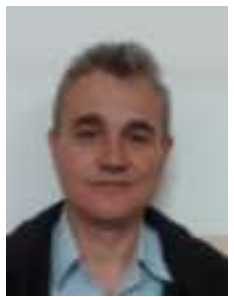

MIHAILA FLORENTIN PhDstudent at University Politehnica of Bucharest. He also works as Stamping Feasibility Analyst Engineer at RENAULT TEHNOLOGIE ROUMANIE for 8 years. 